\title{
71 TRANSFORMING ATTITUDES: A YOUTH INITIATIVE
}

J Trimboli, ${ }^{1}$ L Anderson, ${ }^{2}$ M Rivere ${ }^{2}$ Calvary Health Care Bethlehem, Victoria, Australia; ${ }^{2}$ Our Lady of Sion Secondary School, Victoria, Australia

\subsection{6/bmjspcare-2013-000491.71}

Background This collaboration enable nine students in Year 11 and two teachers from Our Lady of Sion College to engage with our patients, their families and staff while exploring a number of topics.

Aim Debunking myths about death, dying and the meaning of Palliative Care.

Methods Patients and family members were interviewed to explore how they have come to understand how the clinical and non-clinical needs of their family members are met.

Results Student Victoria reflects on her experiences 'I could use the clichéd phrase "it changed my life, but in all reality, it did so much more than that. I learnt that hospitals do not have to be places that are starchwhite and unfriendly nor do doctors and nurses have to be people to fear. I learnt that courage is an intangible, amazing force that comes from the most unlikely people and places. I learnt that death does not have to be feared; especially not when it could be embraced. I learnt that it is possible for death, the end of someone's life, to be a celebration; a celebration of the life that has occurred rather than the death itself...Finally, I learnt to see past the physical or intellectual disabilities and see the person who is inside. The courageous, friendly, funny, intelligent, remarkable person that they truly are".

Discussion The students, their families and the school community have a new understanding of Palliative Care. Conclusion This process can be taught to other health care providers-it will create changes in thinking in the community. 